\title{
ANÁLISE DA OCORRÊNCIA DE PATOLOGIAS NOS PAVIMENTOS DE RODOVIAS EM TRAVESSIA URBANA EM GURUPI - TO
}

\section{ARTIGO ORIGINAL}

MARIANO, Marina Reis ${ }^{1}$

ADORNO, Mirielli Sousa ${ }^{2}$

FONSECA, Luiz Felipe da Silva da ${ }^{3}$

MARIANO, Marina Reis. ADORNO, Mirielli Sousa. FONSECA, Luiz Felipe da Silva da. Análise da ocorrência de patologias nos pavimentos de Rodovias em Travessia Urbana em Gurupi - TO. Revista Científica Multidisciplinar Núcleo do Conhecimento. Ano 05, Ed. 11, Vol. 18, pp. 05-22. Novembro de 2020. ISSN: 2448-0959, Link de acesso:https://www.nucleodoconhecimento.com.br/sem-categoria/analise-daocorrencia

\section{RESUMO}

O presente artigo tem como objetivo evidenciar as patologias existentes nos pavimentos das ruas da cidade de Gurupi - TO, bem como a sugestão de soluções para estes problemas. Dentre os pavimentos a serem analisados, destacou-se a Avenida Goiás, que é o trecho urbano da BR-242 que atravessa o município, que apresenta várias patologias pelo grande movimento do centro comercial e pelo tráfego de veículos pesados.

\footnotetext{
${ }^{1}$ Estudante de Engenharia Civil.

${ }^{2}$ Estudante de Engenharia Civil.

${ }^{3}$ Orientador. Mestrado em Engenharia Civil. Especialização em Especialização em Gestão em Administração Pública. Graduação em Administração Pública. Graduação em Engenharia Civil.
} 
Palavras-chaves: Pavimento, patologias, rodovia.

\section{INTRODUÇÃO}

Pavimento, segundo Bernucci (2006) é uma estrutura de múltiplas camadas, constituída após a terraplenagem que tem como função resistir os esforços providos do tráfego e do clima, e que deve garantir o conforto, economia e segurança.

O município de Gurupi - TO encontra-se em um processo de pavimentação das vias públicas, visto que ainda dispõe de ruas sem qualquer calçamento até os dias de hoje, trazendo sérios problemas para trafegar devido aos buracos, lixo e vegetações situadas no local. Além deste contratempo, encontra-se várias patologias onde já existem pavimentação, principalmente onde há um grande fluxo de veículos.

Em grande parte da travessia urbana, a Avenida Goiás, principal avenida da cidade de Gurupi que é coincidente com o segmento da Rodovia BR-242, existem algumas patologias evidentes, principalmente remendos, ondulações e escorregamentos que prejudicam a circulação de veículos e pedestres. Por tratar-se de uma avenida com um grande fluxo de movimentação, é necessário um reparo adequado para impedir possíveis acidentes e desconforto no trânsito.

Neste estudo, buscou-se mostrar a importância da interação tráfego-pavimento, numa tentativa de demonstrar a problemática da ocorrência de determinados defeitos no pavimento ao longo da travessia urbana de Gurupi, buscando identificar possíveis causas e soluções mais adequadas.

\section{FUNDAMENTAÇÃO TEÓRICA}

Importante mencionar a finalidade da pavimentação antes de seguir com o desenvolvimento deste trabalho. Diz Croney (1977) que o pavimento se torna necessário quando o solo não consegue mais suportar as cargas da mesma maneira. Para resistir esses esforços, o material asfáltico precisa ser construído sobre o subleito dividindo as cargas às suas camadas. 
Os tipos de pavimentos são comumente designados rígidos, semi-rígidos e flexíveis. O presente artigo tem por intuito discorrer sobre os pavimentos flexíveis (tipo de pavimento utilizado na rodovia base para pesquisa de campo).

\subsection{ELEMENTOS DO PAVIMENTO}

Sobre as características e divisões das camadas da pavimentação, de acordo com o Departamento Nacional de Infraestrutura de Transporte - DNIT (2006), entende-se que, seguidamente à terraplenagem, são construídas as camadas de pavimentos ( base, sub-base, reforço de subleito e subleito) para facilitar o tráfego de pedestres e motoristas e principalmente para resistir às cargas procedentes dos veículos.

Segundo (DNER, 2017), as definições de cada camada são:

- Revestimento: também chamada de capa de rolamento, é a camada que recebe diretamente as ações verticais e horizontais dos veículos.

- Base: camada disposta a resistir aos esforços verticais oriundos dos veículos, distribuindo-os ao subleito, e sobre a qual se constrói o revestimento;

- Sub-base: camada corretiva do subleito e complementar à base, com as mesmas funções desta, e executada quando, por razões de ordem econômica, for conveniente reduzir a espessura de base;

- Reforço de subleito: camada granular do pavimento executada com o objetivo de melhorar a capacidade de suporte de carga do subleito e de reduzir espessura da sub-base;

- Subleito - é o terreno de fundação do pavimento.

\subsection{PAVIMENTO FLEXÍVEL}

Em se tratando de pavimentos flexíveis, o Departamento Nacional de Infraestrutura de Transporte - DNIT (2006) afirma que é uma estrutura com um misto de camadas a fim de distribuir estes esforços para a camada que fica em contato com os veículos e pedestres, composto por uma mistura de solos e materiais granulares. 
Figura 1 - Resposta mecânica do pavimento flexível

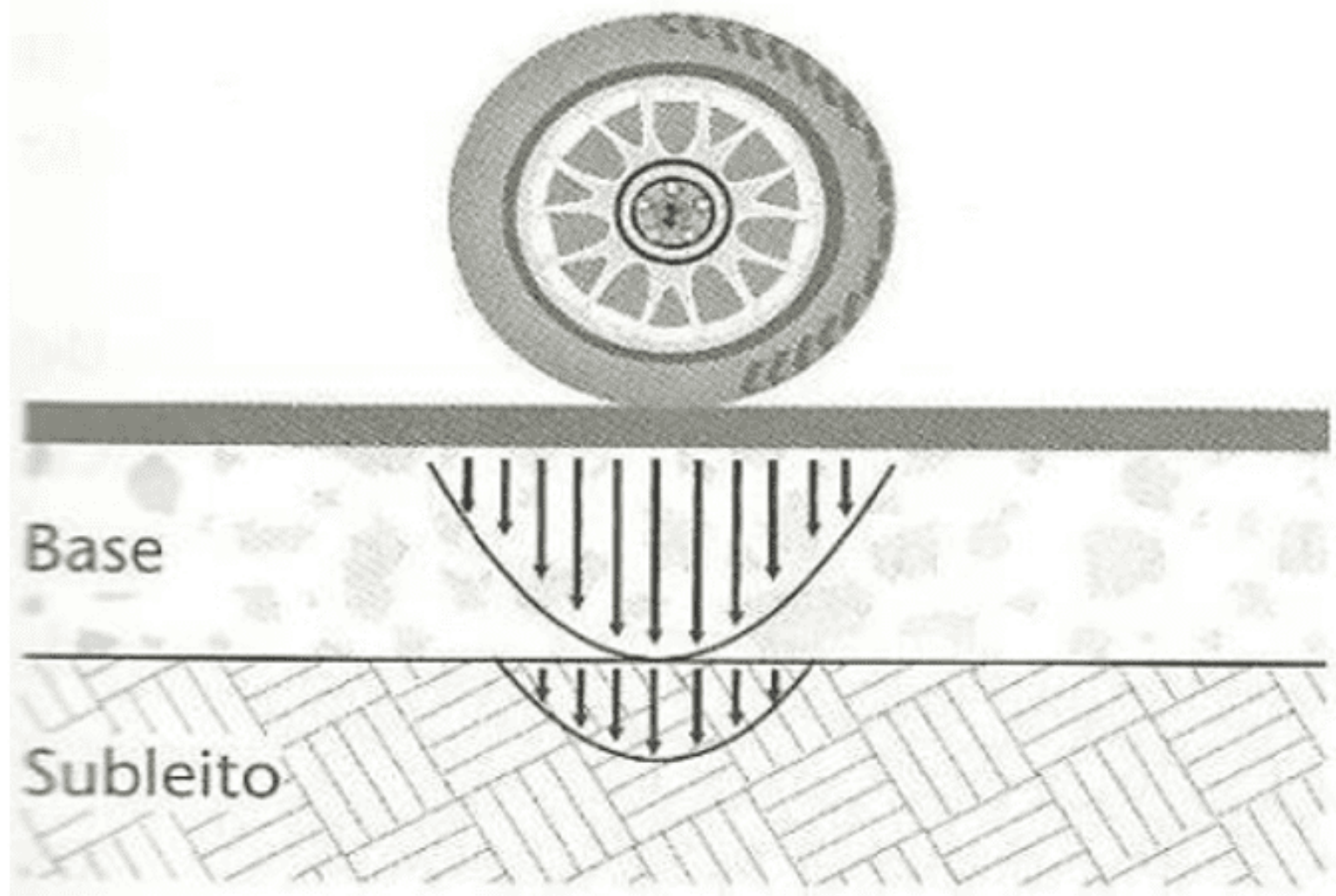

Fonte: Balbo (2007).

Bernucci et al. (2010) menciona que existem as misturas usinadas (agregados e ligante), fabricadas em uma usina estacionária, e depois transportada ao local desejado.

Referente ao Cbuq, é vista por Satel (2016), como o revestimento mais operado em rodovias e vias urbanas. É formado por agregado graduado, de enchimento e ligante betuminoso, posteriormente é espalhado e compactado a quente por rolos até alcançar a textura e compacidade definido no projeto. É muito utilizado pela sua rapidez e fácil manutenção.

\subsection{PATOLOGIAS EM PAVIMENTAÇÃO ASFÁLTICA}


Conforme afirma Castro (2009), patologias em pavimentações são modificações na parte superficial ou nas camadas da estrutura de um pavimento, de forma que modifique de forma negativa, alterando o seu desempenho.

Dentre os fatores que contribuem para o surgimento de patologias em pavimentação, afetando a sua funcionalidade, os três principais são:

- Projeto inadequado: materiais e medidas inadequados para o tráfego estabelecido em projeto; materiais utilizados fora das especificações padrões; execução da obra fora das espessuras pré-estabelecidas em cálculos;

- Intemperismo: refere-se ao conjunto de agentes biológicos, químicos e físicos (naturais), que atua sobre os elementos básicos que constituem um pavimento: asfalto e agregado, onde o primeiro é o que sofre mais impacto da ação da oxidação e da ação da água, que destrói suas propriedades mecânicas;

- Tráfego: o desgaste ocasionado pela ação abrasiva dos pneus do tráfego de veículos causa deformações elásticas no pavimento, provocando a aparição de rupturas em sua estrutura.

Os defeitos de uma pavimentação podem ser classificados em dois tipos:

- Relacionados ao comportamento estrutural: trincas, instabilidade desagregação;

- Relacionados ao conforto e à segurança do usuário: deformações superficiais (superfícies molhadas tornam-se derrapantes).

Já a deformação plástica, também ocasionada pela ação do tráfego na superfície do revestimento asfáltico, causa uma grande variedade de patologias, todavia, as que foram encontradas na Avenida Goiás para o estudo de caso deste trabalho foram as seguintes: remendos, ondulações e escorregamentos.

- Ondulações: são os deslocamentos plásticos do pavimento, caracterizados pelo formato ondas grandes na superfície;

Figura 2 - Ondulações próximo ao meio fio. 


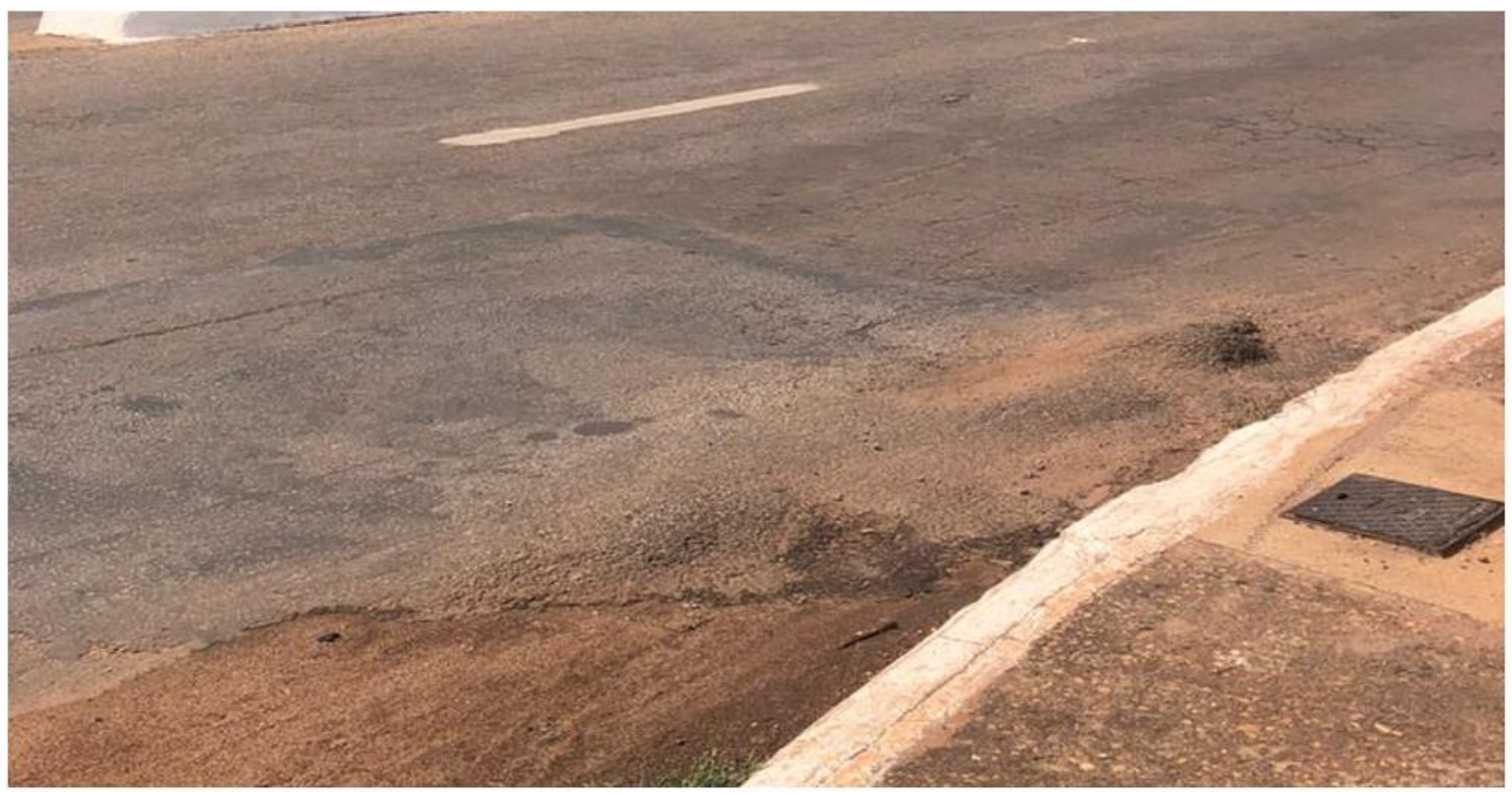

Fonte: Acervo dos autores (2020).

- Escorregamento: são os deslocamentos plásticos do revestimento asfáltico, com a aparência de uma onda, formando uma intumescência (inchaço) no local.

Figura 3 - Escorregamento próximo a uma lombada

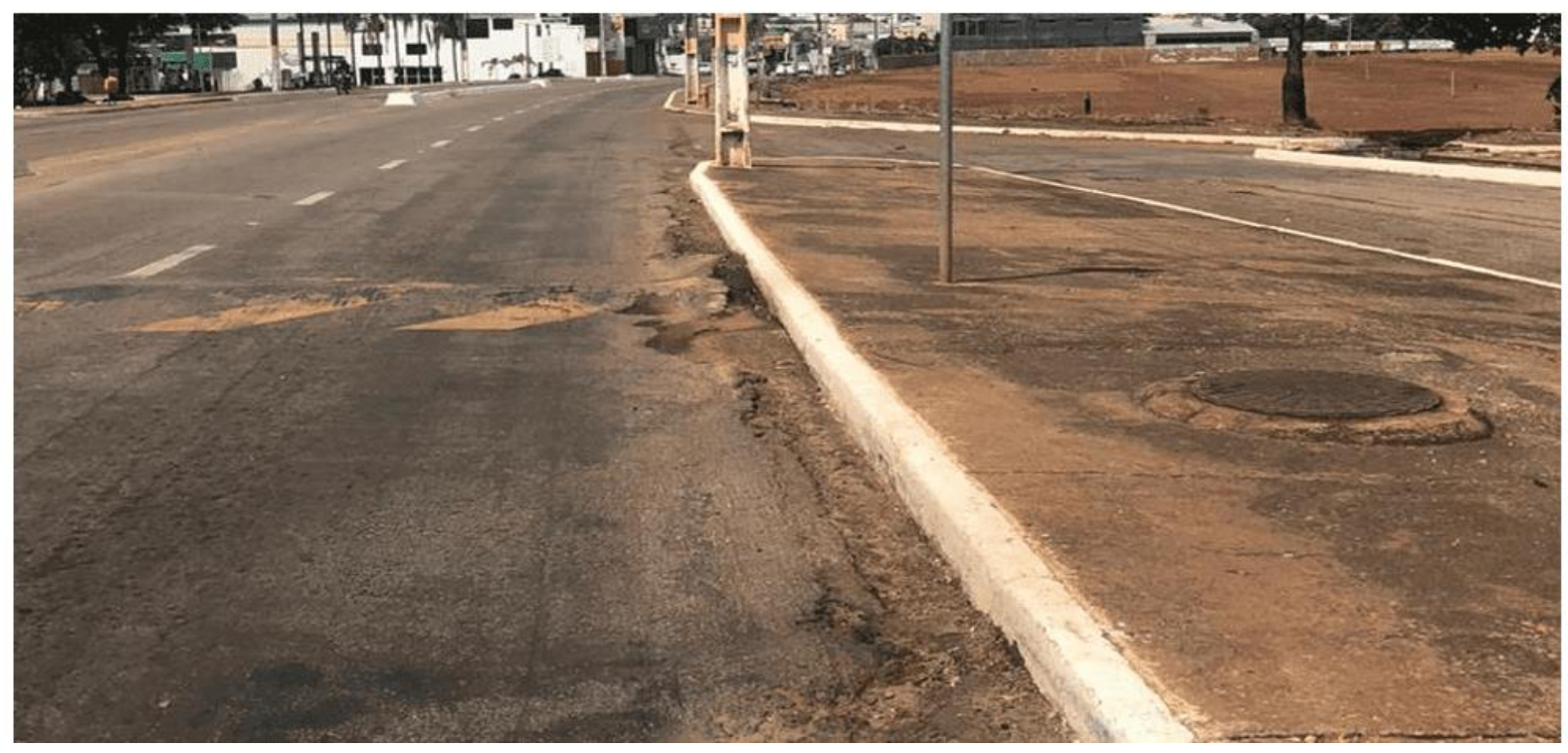

Fonte: Acervo dos autores (2020). 
- Remendos: são patologias que consistem no preenchimento de buracos ou depressões, com massa asfáltica. Quando mal executado, gera um desnível com o pavimento provocando desconforto para os usuários da via.

Figura 4 - Remendo situado na Avenida Goiás

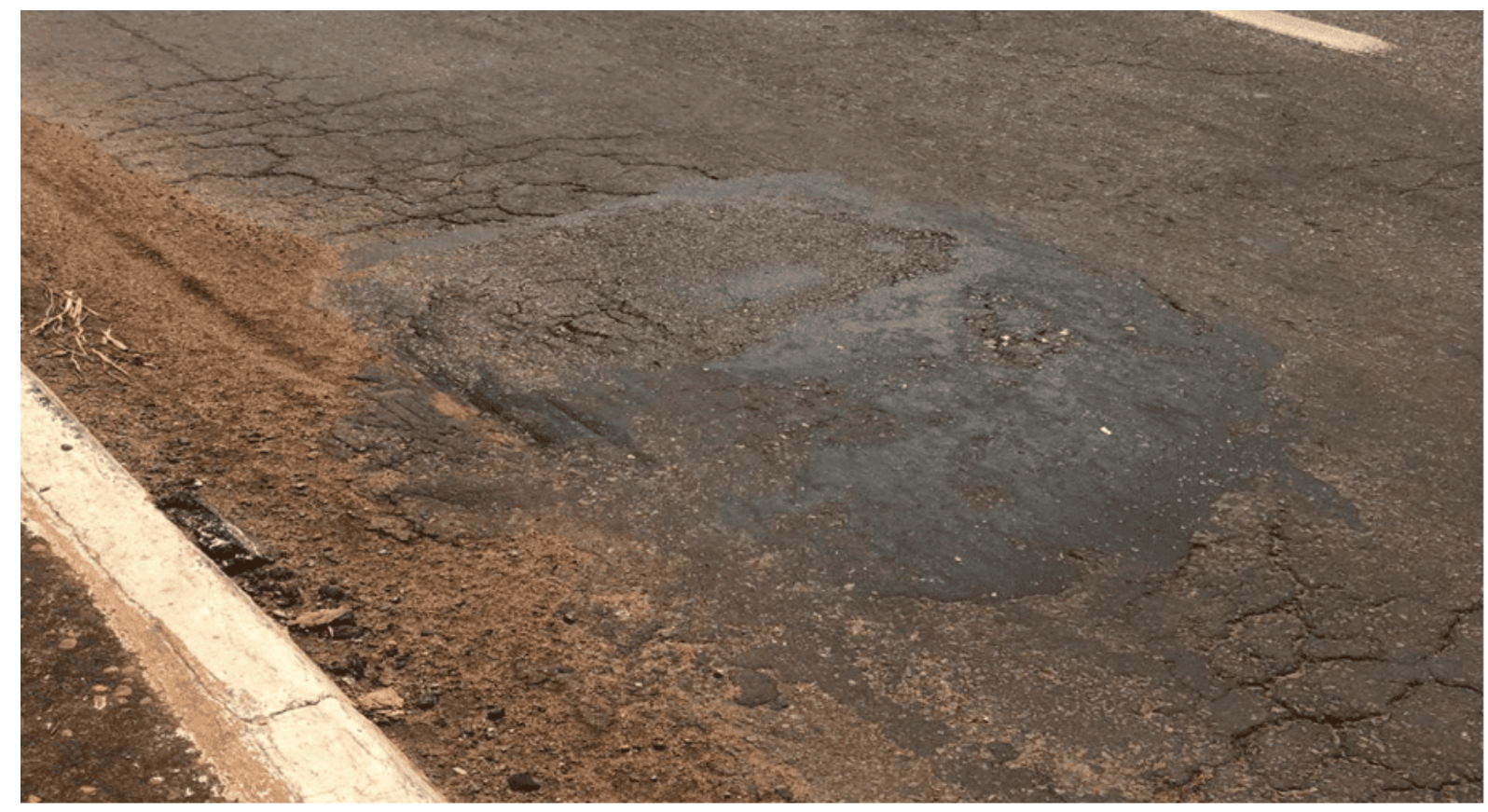

Fonte: Acervo dos autores (2020).

\subsection{TRÁFEGO EM TRAVESSIA URBANA NA AVENIDA GOIÁS}

Para Ramos (2017), as vias de tráfego urbano, mesmo bem projetadas e construídas necessitam de manutenção para que apresentem bons desempenhos ao longo de sua vida útil, o que influencia diretamente no desenvolvimento da economia, pelo fato de ser o principal meio de transporte (terrestre), pois as más condições das vias aumentam os custos de manutenção e operacionais.

O município de Gurupi, situado ao sul do Estado do Tocantins, está localizado entre duas vias federais: rodovias BR-153 e BR-242. Ambas as rodovias possuem um alto fluxo de veículos, e uma grande parte deles são veículos pesados, como caminhões e ônibus; isso se decorre ao fato de serem vias comerciais importantes que atravessam o país de norte a sul. 
O pavimento asfáltico de Gurupi sofre mudanças em sua composição física sobretudo no verão pela temperatura elevada, assim provocando amolecimento no revestimento e com o deslocamento contínuo do tráfego, manifestam-se patologias consequente desses desgastes e ocorrem mudanças mais aparente no revestimento superficial.

Além da variação climática e peso excessivo, Ramos (2017) afirma que:

Os materiais que compõem o revestimento asfáltico infelizmente possuem vida útil de projeto, posteriormente podem perder suas propriedades físicas e de resistência, gerando problemas nos revestimentos, e percebe-se que em época de chuva esses problemas de falta de drenagem aparecem mais e o número de patologias nas pistas aumenta consideravelmente (RAMOS, 2017).

As más condições da superfície de rolamento das rodovias, com depressões, recalques e/ou panelas podem levar às perdas de estabilidade e aderência do pneu/pavimento e, refletirá na dificuldade em manter os veículos na trajetória que se deseja (ZAGONEL, 2013).

Figura 5 - Acúmulo de terra e entulho devido a enxurrada.

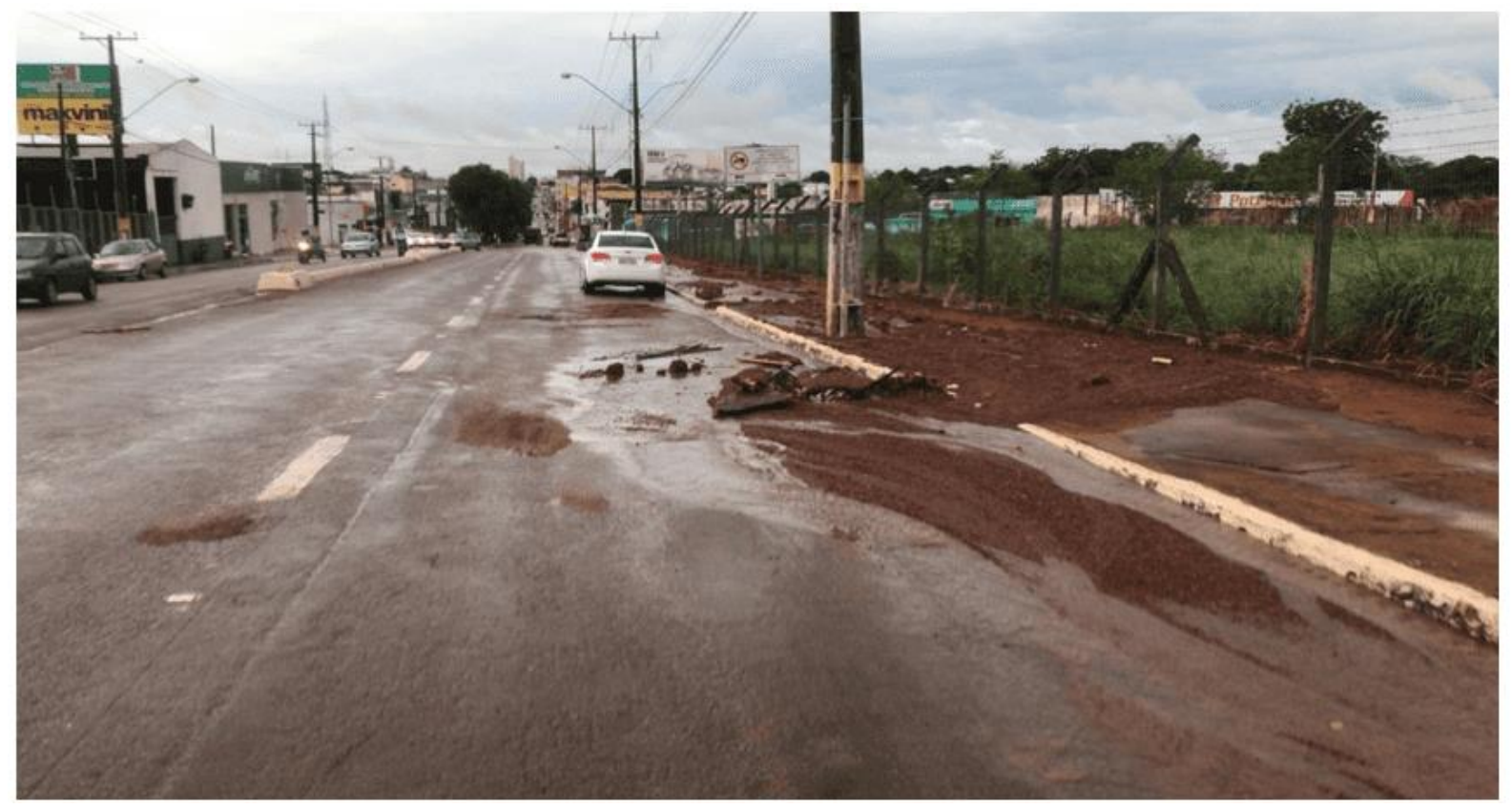

Fonte: Acervo dos autores (2020).

Figura 6 - Veículo pesado em trecho da Avenida Goiás com acúmulo de terra. 


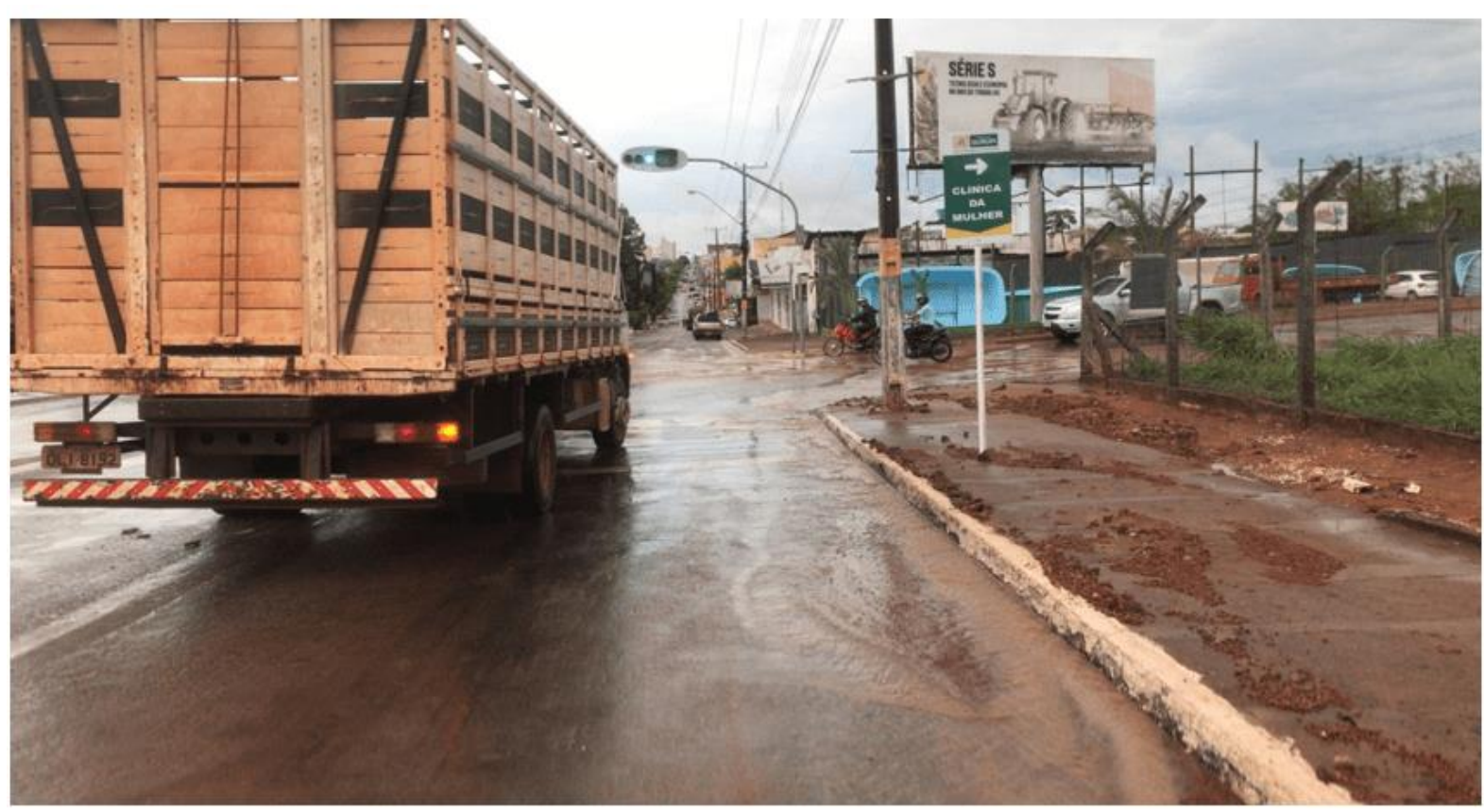

Fonte: Acervo dos autores (2020).

Figura 7 - Limpeza do excesso de terra carregado pela enxurrada na Avenida Goiás. 


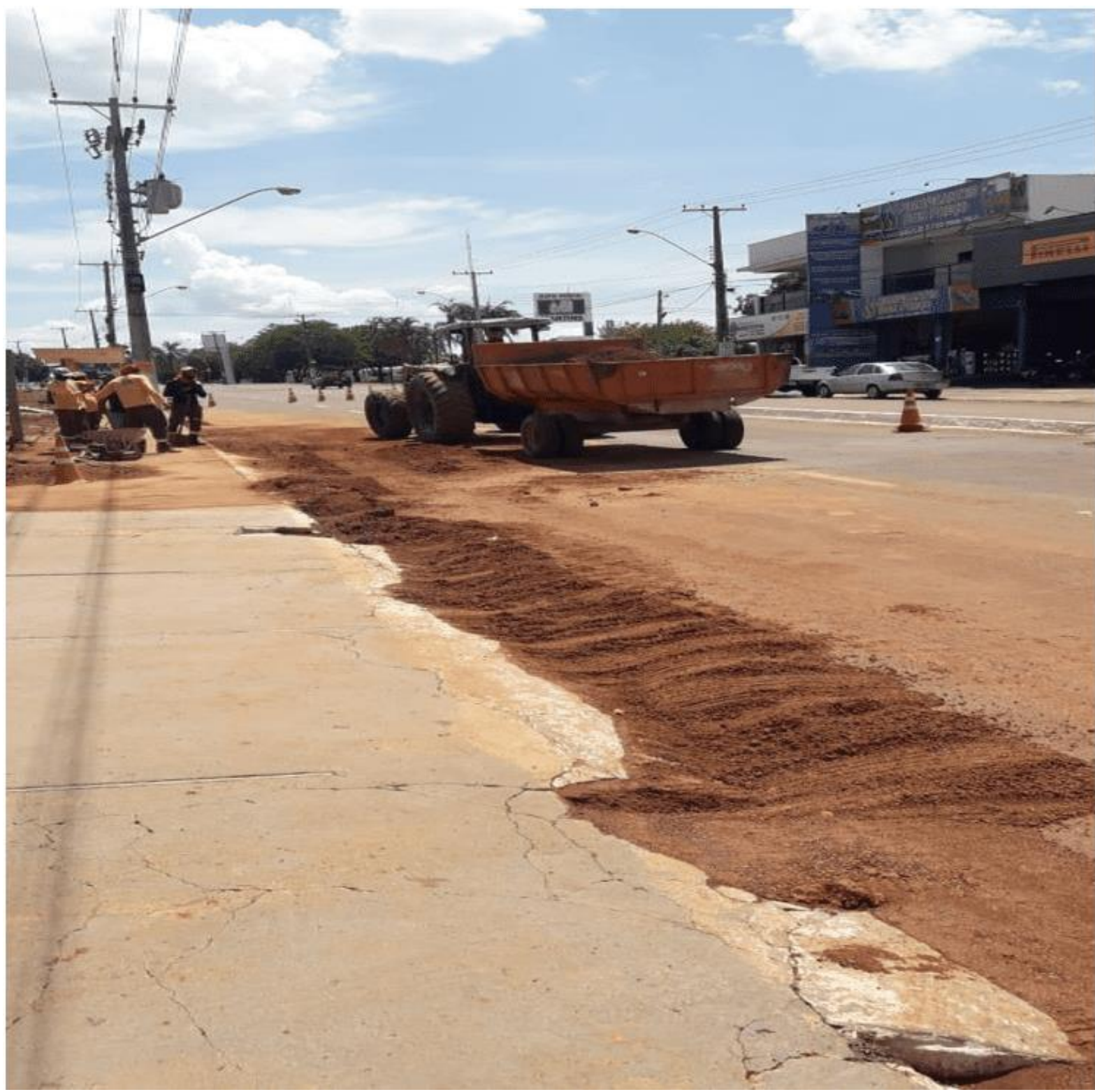

Fonte: Acervo dos autores (2020).

\section{MATERIAIS E MÉTODOS}

A metodologia empregada neste artigo fundamentou-se em um estudo bibliográfico, com base em livros, artigos e normas relacionados às patologias em pavimentação asfáltica, com ênfase naquelas encontradas no estudo de caso realizado nas rodovias urbanas da cidade de Gurupi-TO. A pesquisa de campo foi fundamental para a coleta de dados e registros fotográficos, com a finalidade de demonstrar as patologias encontradas. 
No estudo de caso, realizado in loco na Avenida Goiás (BR-242), foram analisadas as condições de trafegabilidade nos meses de outubro a novembro. Notou-se diversos tipos de defeitos na estrutura do pavimento onde as principais patologias encontradas foram ondulações, escorregamentos e remendos que foram descritas no decorrer do artigo. A população estimada do município, segundo a última atualização do IBGE deste ano, é de 87.545 pessoas.

Figura 8 - Trecho da Avenida Goiás (BR-242) objeto de análise da pesquisa

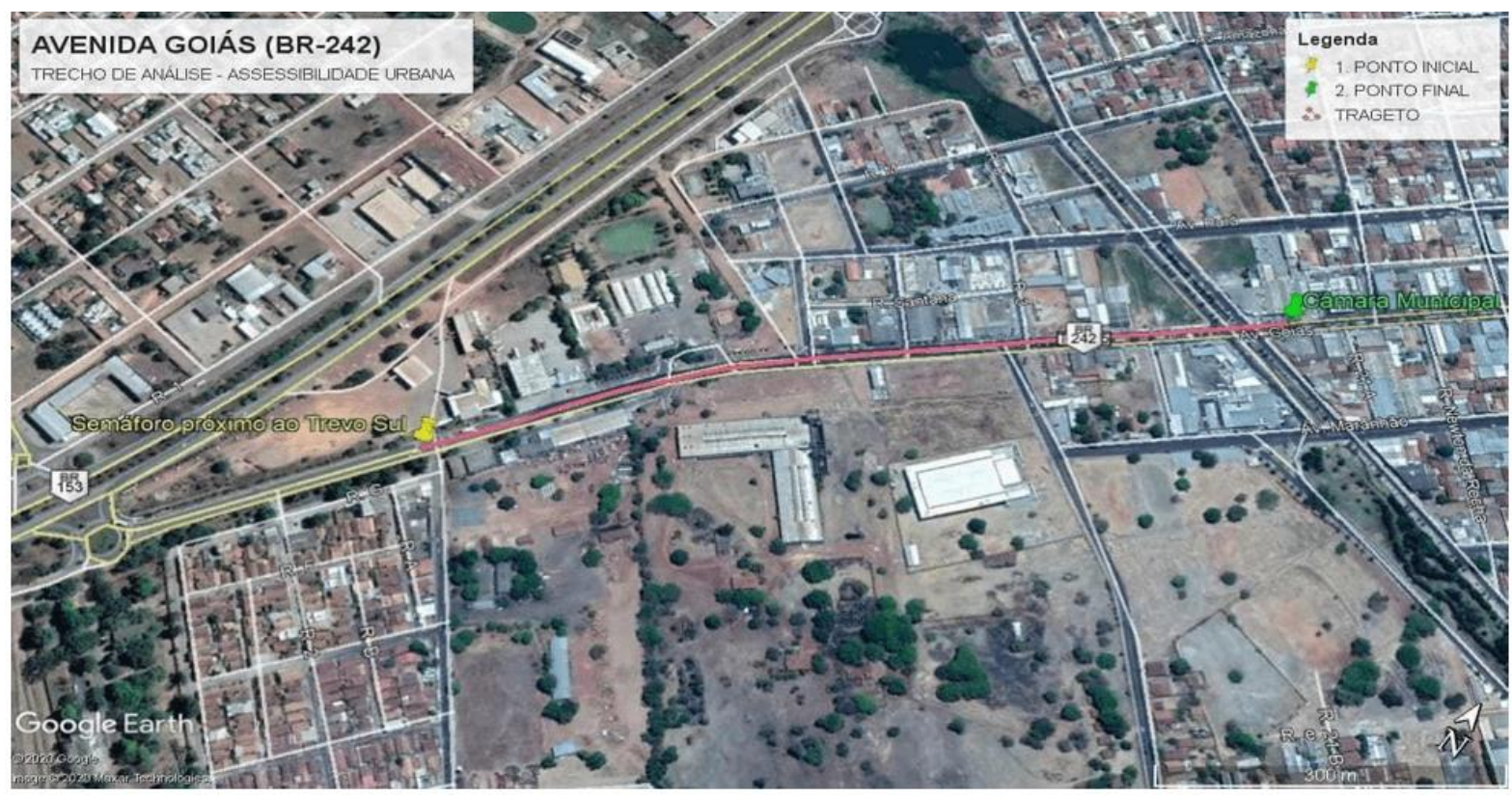

Fonte: Rodrigues et. al, 2020.

Não foi necessário a aprovação junto ao Comitê de Ética em Pesquisa, segundo a resolução 466/2012, pois trata-se de uma pesquisa da qual as referências foram obtidas em materiais já publicados e colocado à disposição na literatura, não havendo, portanto, influência direta aos seres humanos.

\section{RESULTADOS E DISCUSSÃO}

De acordo com o Departamento Nacional de Infraestrutura de Transportes - DNIT (2006), a manutenção preventiva é o conjunto de operações de conservação realizadas periodicamente, no objetivo de evitar o surgimento e o agravamento de defeitos. 
Analisando os aspectos das patologias encontradas na Avenida Goiás, principalmente os remendos, percebe-se que o órgão responsável pela manutenção (DNIT) realiza os reparos ocasionalmente quando o pavimento se encontra deteriorado num estágio mais avançado.

No mês de setembro de 2020 foi realizada uma fresagem no cruzamento da avenida, que consiste em remover o pavimento antigo substituindo-o por um novo, para melhorar as condições de trafegabilidade das vias urbanas, como está representado nas figuras 9,10 e 11 .

Figura 9 - Fresagem e recomposição BR 242 perímetro urbano

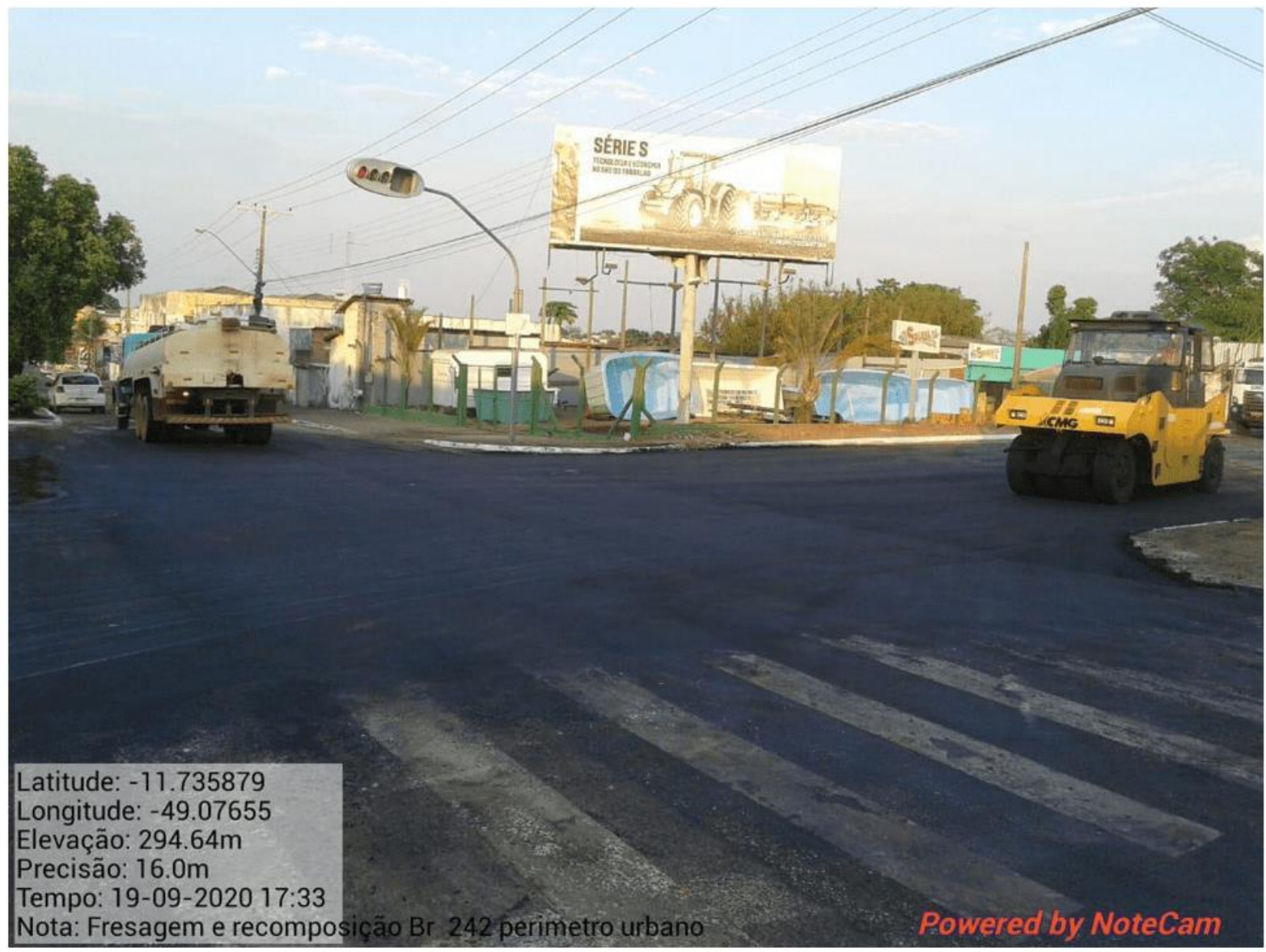

Fonte: Fonseca (2020)

Figura 10 - Fresagem e recomposição BR 242 perímetro urbano 


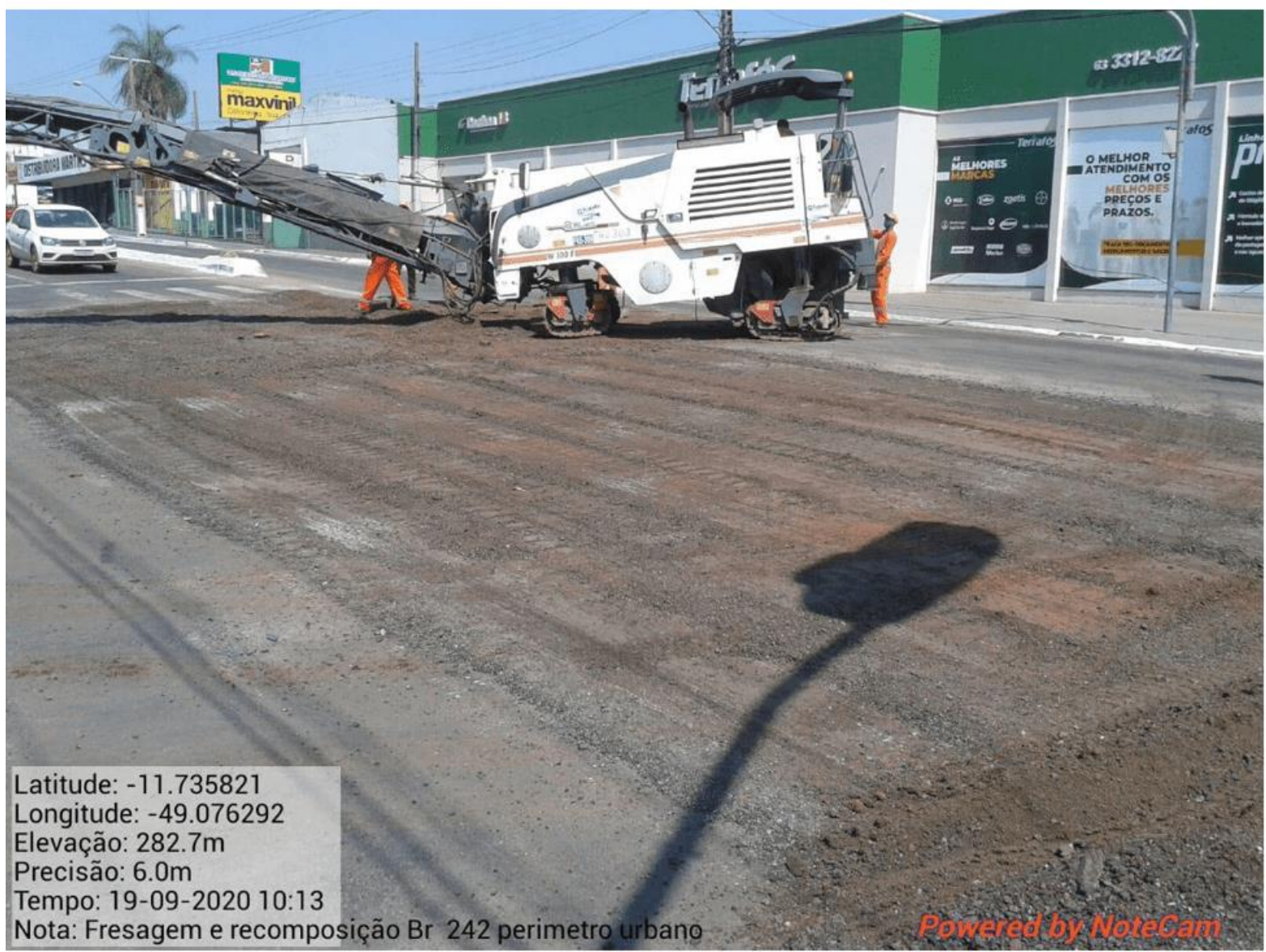

Fonte: Fonseca (2020)

Figura 11 - Fresagem e recomposição BR 242 perímetro urbano 


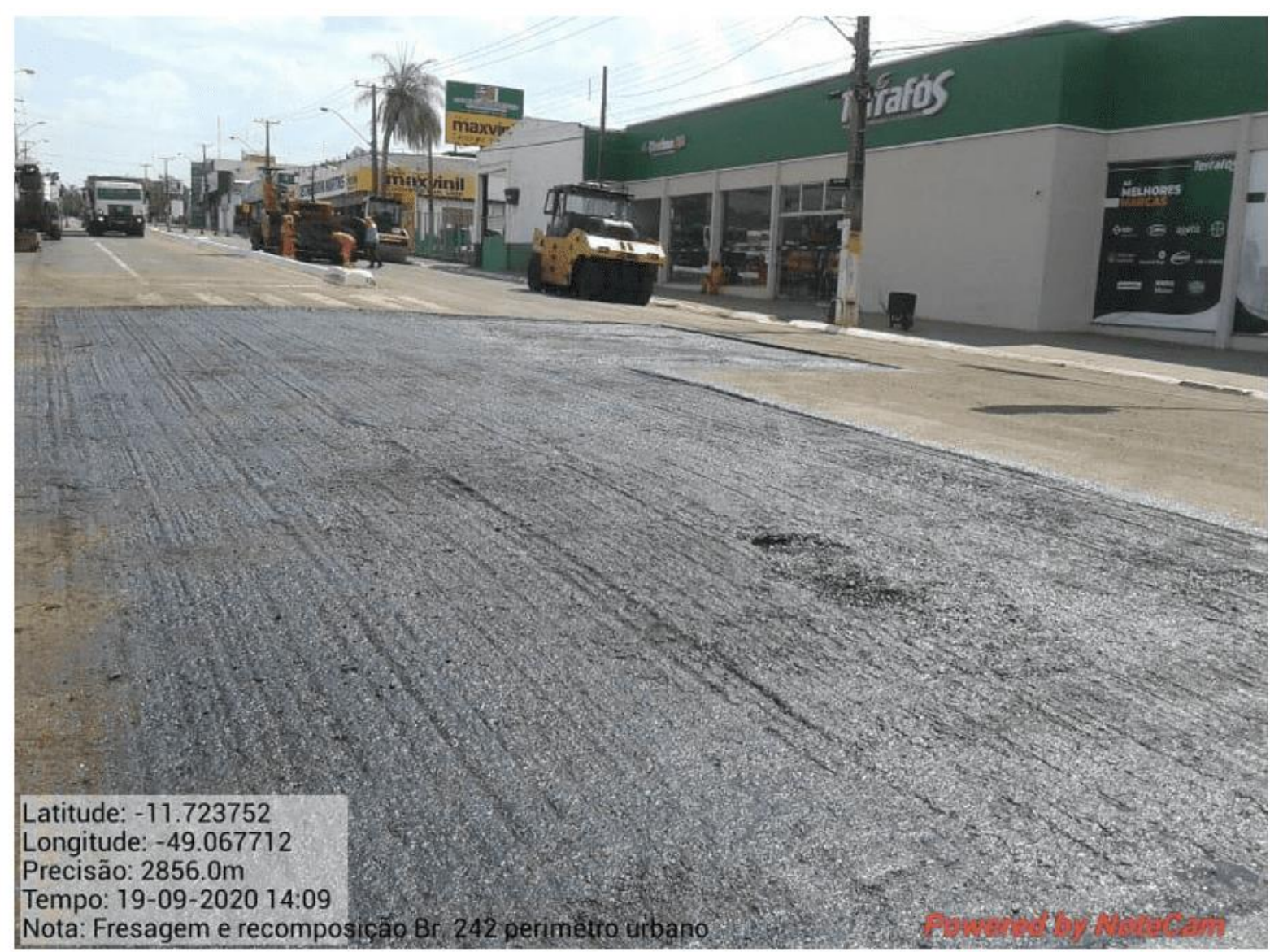

Fonte: Fonseca (2020)

Analisando a manutenção realizada no mês de setembro e os dados coletados nos meses de outubro e novembro, nota-se que o trabalho realizado não foi duradouro. Contudo, diversos fatores podem influenciar para que isto ocorra em qualquer obra de pavimentação; neste caso, as principais causas foram a alta variação de temperatura e tráfego intenso no local.

Sobre restauração do pavimento asfáltico, Gonçalves (1997) certifica que:

É o processo de se trazer a condição funcional a níveis aceitáveis por meio de intervenções que sejam técnica e economicamente adequadas, o que implica em que a durabilidade e o desempenho da solução implementada devam atender a requisitos mínimos, além de levarem a um retorno máximo do investimento realizado, dentro das restrições técnicas e operacionais existentes. A restauração requer, portanto, a execução de um projeto de engenharia completo e consistente (GONÇALVES, 1997). 
Existem muitas soluções de prevenção, no entanto, estas reformas necessitam de condições voltadas ao pavimento, trafegabilidade e materiais e equipamentos adequados e de fácil alcance. De acordo com o Departamento Nacional de Infraestrutura de Transportes - DNIT (2006):

[...] a manutenção preventiva desempenha um papel fundamental no que se refere à conservação das rodovias, porquanto poderá melhorar o desempenho do pavimento e, consequentemente, reduzir gastos posteriores. De tal modo, percebe-se que a manutenção preventiva tem como alvo principal não de reparar defeitos apresentados na rodovia, mas, sim, impedir que as patologias venham a ocorrer (DNIT 2005).

\section{CONSIDERAÇÕES FINAIS}

Neste estudo foi realizada uma pesquisa puramente bibliográfica em conjunto com imagens obtidas in loco com a finalidade de destacar as principais patologias localizadas na Avenida Goiás (BR-242), demonstrando suas principais causas e restauração dos pavimentos danificados.

À vista disso, o objetivo principal do estudo foi atingido, uma vez que foi possível identificar de forma clara as patologias encontradas no trecho, sobretudo as definições de cada elemento do pavimento e expondo as condições de trafegabilidade de motoristas e pedestres em travessia urbana.

O estudo mostrou que os reparos superficiais - realizados pelo órgão federal responsável, o DNIT - solucionaram os problemas, no entanto com pouca duração, uma vez que fatores como condições climáticas e grande movimentação de veículos pesados também contribuem para a diminuição da qualidade do pavimento recém consertado. Dito isto, concluiu-se que a duração de uma pavimentação não depende apenas de um projeto bem feito, boa execução da obra e a escolha de bons materiais, mas também de um conjunto de fatores que, de certa forma, interferem na qualidade e vida útil das rodovias.

\section{REFERÊNCIAS BIBLIOGRÁFICAS}


BALBO, José Tadeu. Pavimentação Asfáltica: Materiais, projetos e restauração. São Paulo, Oficina de Textos, 2007.

BERNUCCI, Liedi Bariani et al. Pavimentação asfáltica: formação básica para engenheiros. Rio de Janeiro: Petrobras: ABEDA, 2006. 504 p.

BERNUCCI, Liedi B.; MOTTA, Laura M. G.; CERATTI, Jorge A. P.; SOARES, Jorge B. Pavimentação Asfáltica - formação básica para engenheiros. 3ª Edição. Rio de Janeiro, Imprinta, 2010.

BRASIL, IBGE - INSTITUTO BRASILEIRO DE GEOGRAFIA E ESTATÍSTICA. Censo Populacional. Disponível em: <https://www.ibge.gov.br/cidades-eestados/to/gurupi.html>. Acesso em: 03 nov. 2020.

CASTRO. Defeito dos pavimentos asfálticos e suas causas. Rio Grande do Sul, 2009.

CRONEY, D. The design and performance of road pavements. London: Her Majesty's Stationery Office, 1977.

Departamento Nacional de Infraestrutura de Transporte - DNIT. Manual de Pavimentação Rodoviária. Instituto de Pesquisas Rodoviárias, Rio de Janeiro, 2006.

Departamento Nacional de Infraestrutura de Transporte - DNIT. Pavimentos flexíveis - Concreto asfáltico - Especificações de serviço - Norma DNIT 031/2006-ES. Instituto de Pesquisas Rodoviárias, Rio de Janeiro, 2006.

Departamento Nacional de Infraestrutura de Transporte - DNIT. Glossário de Termos Técnicos Rodoviários. Instituto de Pesquisas Rodoviárias, Rio de Janeiro, 2017.

Departamento Nacional de Infraestrutura de Transporte - DNIT. Manual de conservação rodoviária. Rio de Janeiro, 2005. 
Figura 8 - RODRIGUES, Miriane dos Santos, SANTOS, Lethícia Anielly Oliveira, FONSECA, Luiz Felipe da Silva da. Acessibilidade urbana: Análise das condições de acesso à pessoa com deficiência e mobilidade reduzida em via pública no centro da Cidade de Gurupi-TO. Revista Científica Multidisciplinar Núcleo do Conhecimento. Ano 05, Ed. 03, Vol. 09, p. 81-101. Março de 2020, 13 p.

Figuras 9,10 e 11 - FONSECA, Luiz Felipe da Silva da. Acervo pessoal. Setembro de 2020.

GONÇALVES, Fernando Pugliero. Utilização de Expert Systems na Manutenção de Pavimentos. Tese M.Sc., ITA, São José dos Campos, 1997.

RAMOS, Dennis Martins. Determinação de patologias em pavimentação asfáltica nas avenidas: Av. Sergipe, Av. Joaquim Aires, Av. das nações unidas em Porto Nacional-TO. Centro Universitário Luterano de Palmas, Palmas-TO, 2017. 15p.

RAMOS, Dennis Martins. Determinação de patologias em pavimentação asfáltica nas avenidas: Av. Sergipe, Av. Joaquim Aires, Av. das nações unidas em Porto Nacional-TO. Centro Universitário Luterano de Palmas, Palmas-TO, 2017. 16 e 17 p.

SATEL Safar Terraplenagem LTDA (2016). “Cbuq, você sabe o que é?”. Disponível em:<https://www.satel.com.br/cbuq-voce-sabe-o-que-e/>. Acesso em: 01 nov. 2020.

ZAGONEL, A. R. Inovações em Revestimentos Asfálticos Utilizados no Brasil. Universidade Regional do Noroeste do Estado do Rio Grande do Sul Departamento de Ciências Exatas e Engenharias. Curso de Graduação em Engenharia Civil ljuí/RS, 2013.

Enviado: Novembro, 2020.

Aprovado: Novembro, 2020. 